\title{
Building the Self. A Contextual Approach
}

\section{Francisco MARTIN-MURCIA**1 \& Rafael FERRO-GARCÍA ${ }^{* *}$}

\author{
(*) Instituto de Ciencias del Comportamiento, Almería, España (**) Centro de Psicología C.E.D.I, \\ Granada, España.
}

(Received on April 2, 2016; Accepted on June 10, 2016)

\begin{abstract}
We propose a review of the formation of the Self from a phenomenological-contextual perspective. This approach is justified as a way of solving the metaphors that are used to understand the formation of the Self, which usually commits either categorical and reification errors or directly aporetic arguments. The concept of the Self is not denied, given the huge reinforcement received by the human organism from infancy to tact with private experiences, and such being-in-contact is precisely the primary phenomenological experience of the Self. A genuinely behavioral explanatory model is presented, understanding the Self as a social epiphenomenon that requires a basic pre-reflective awareness in a particular cultural context that will shape it through prototypical verbal behavior in human interaction. Finally, the different stages of Self-learning are described. The discussion underlines the extraordinary importance of understanding the Self in terms of perspective, which leads to the parsimonious comprehension of the classic features attributed to the Self, such as constancy, timelessness, transcendence and interiority without elaborating mental constructs.
\end{abstract}

Keywords: Phenomenology, Behaviorism, Self, Verbal behavior.

\section{Construyendo el Yo: un enfoque contextual}

RESUMEN: Se plantea una reconsideración de la formación del Yo desde una perspectiva fenomenológica-contextual. Se justifica dicho enfoque como una forma de resolución de las metáforas que suelen utilizarse para entender la formación de la ipseidad, en las que habitualmente se cae tanto en errores categoriales y de reificación o directamente en argumentos aporéticos. No se reniega del concepto, dado el enorme reforzamiento recibido en los organismos humanos a contactar desde la infancia con las experiencias privadas y ese estar-en-contacto es precisamente la experiencia fenomenológica primaria del Yo. Se presenta un modelo explicativo genuinamente conductual, entendiendo el Yo como un epifenómeno social que requiere una conciencia básica pre-reflexiva en un contexto cultural determinado que le dará forma a través de la conducta verbal prototípica en la interacción humana. Por último, se describen las distintas etapas del aprendizaje del Yo. Se enfatiza en la discusión la extraordinaria importancia de una comprensión del Yo en términos de perspectiva ya que permite entender de forma parsimoniosa las clásicas características atribuidas al mismo, como constancia, atemporalidad, trascendencia e interioridad sin necesidad de elaborar constructos mentales. Palabras clave: fenomenología, conductismo, Yo, conducta verbal.

${ }^{1}$ Correspondence: Avda. Carlos III 432, 7º 04720 Aguadulce (Spain). E-mail: psicologo@me.com. Phone: +34607899629. 
The Self is an issue of primordial importance in psychology (along with the conscience), but as ambiguous as slippery (Zhao, 2014). The self is also about as vexing a construct as there is in psychology (Raeff, 2010). Not in vain, Popper notes that since Hume up to the present, "the existence of the Self has been considered very problematic" (Popper \& Eccles, 1983). Even more, a fundamental debate exists as a result the self is made of universal properties or wheter is culture-dependent (Bukobza, 2007).

Although not the first one, Freud probably began the arduous work of dealing with it when he defined it in the second topic as a part of the personality that is organized as a result of the family and the social environment. It is the result of the drama of life, in which the flesh fights to clear a way through moral-social events, and the Self would-on principle-be in charge of the difficult escape from that reality (Freud, 1924). The formation of the Self that would allow one to stand up to both tensions needs to be explained. Such formation is presumed, given that the realities_on principle, as Freud insists-are extremely heterogeneous in spite of the fact that people in general have many things in common (for example wellregulated cultures and similar bodies). This has been addressed by neuroscience, to mention the academy with more presence and weight in modern society. So, the Self has been substantiated, apparently finding the locus of the autobiographical Self in some of the brain's functions; it would seem that the Cartesian pineal gland has been modernized. It may be suggested that the so-called resolution of dualism by a rude materialistic monism still requires more intellectual work (Bennet, Dennet, Hacker \& Searle, 2009). The representational psychologies (although they refer to neurons that create the Self) lead to aporetic situations in which there is a clear, objective reasoning difficulty. In spite of the legitimate objectivist intention of the heir proposal of Descartes, that is, the necessary assessment of the confusing and subjective phenomenal experience (formerly provided by psychophysics and currently by neuroimaging), the truth is that such experience embodied in the Self requires a You. As has been has mentioned, even Freud realized that the Ego is the result of the struggle between the body and culture. He ventured to seek personal identity in the process of the dramatic struggle between the Ego and the Super-Ego-by the way, a dynamic similar to Popper's (Popper \& Eccles, 1983) interaction between world 1 and 3 with world 2 .

In any event, the Self is an essential theme that has been referred to, and attempts have been made to describe it. In any case, a person becomes a person because there are other people (if there were wolves, we would be wolves). If the Self emanated from some place, it would be precisely from the social context (existing before the individual) and from the verbal community of reference.

Phenomenology and radical behaviorism, with a common philosophical essence (Fuentes \& Robles, 1992), could be a way of providing the conditions to comprehend and explain the Self, as both of them could be a method to confirm, describe, and explain the psychological experience-basically, the phenomenon itself. The explanation of the psychological event will be found in the triple contingency relationship behavior-situation-reinforcer (regardless of how one describes this relation verbally).

There are different formats that could somehow explain the problematic dimension that is essentially the psyche, and, at the same time, fit within the effective psychologies; behavioral approach is one of them (Kohlenberg \& Tsai, 1991). 


\section{A theory of the formation of the Ipseity}

It is appropriate to consider the formation of the Self from this perspective, given that is a ubiquitous topic both in daily life and in therapy sessions (e.g., "I don't feel like myself", "I don't know who I am", "I have so many faces that I don't know which one is the real one", "you must be yourself", "nobody really knows me", "sometimes, I act without being myself").

The experience of one-self is absolutely transcendent in the psychological development of individuals. Human organisms learn to con-tact with private experience, and this is precisely one of the behaviors that makes us person. As mentioned, this highly reinforced being-incontact from childhood is precisely the primary phenomenological experience of the Self. It is therefore undeniable that the experience of one-self exists as one of the quintessential psychological phenomena in human organisms (Barresi, 2012).

This approach presents a theory of learning which draws on the early writings of Skinner (1953, 1957) about how our private experiences are generated, understanding the Self as a social epiphenomenon, a product of verbal behavior embodied in a physical body. The explanatory model is based on the early verbal experiences of the verbal relations $I$, me, and other equivalents.

Kohlenberg \& Tsai (1991) describe four classical ways of understanding the Self: as the experience of the self as me or a permanent sense of oneself; as the source of one's actions (the organizing force that appears in the situation "I want to help you", for example); as the source of the spontaneous and creative gestures or actions; and lastly, as personal identity (selfawareness and self-perception). Undoubtedly, these notions of the Self are easily assimilated, as they are a part of our family, literary, and cinematographic verbal frameworks. We intuitively know what is meant because we have had similar experiences that can lead to the intuitive idea of the Self as the "cause" of behavior. The radical behaviorist paradigm does not agree with this causal assumption. Obviously, it does not deny having certain experiences of the self in these terms, but it denies considering this psychological experience (the Self) as a mental entity that generates behaviors.

There are some elements present at the onset of the oral report "I..." as a functional unit that help us to understand the process. For instance, the discriminant stimulus (the example proposed is an apple), a response, and some reinforcement can be distinguished. Some public stimuli (the apple, other people, the child) and also some stimuli that are private for the person are present in the situation. Lastly, the perspective or spatial relation between the child and the external objects, the child's orientation towards the stimulus and the process of naming or tacting the stimulus "I see the apple", and the consequence or social response, "that's right" (not forgetting the private stimulation of one's own activity of seeing, as mentioned).

The acquisition of this oral report "I" is equivalent to learning concepts in which one characteristic of the stimuli indirectly emerges as the relevant stimulus through the behavior of responding to that characteristic (for example the concept of small, a characteristic of a pail compared to another pail, a glass to another glass, one child with another child, etc.). The Self emerges as an independent unit from previously learned longer phrases containing " $I$ " during 
the child's development through verbal learning. Three stages of the development of verbal behavior have been proposed that it would lead to the emergence of the Self.

Stage 1 is the learning of large functional units, which usually occurs during the first two years of life. After the first learnings of small units such as: "mamma", "water", "car", the parents tend to teach the child longer phrases that can be learned as a whole, for example: "I see water", "I have a car", etc. These phrases not only describe the object but also a private activity of the child (because the experience of seeing water is private to the child). It is a complex experience requiring, as previously mentioned, different stimuli and responses, such as the presence of the father, the water, the child's orientation to the stimulus, the perspective between the child and the objects, of the experience of "seeing" the water (probably a confusing experience that will require a very complex learning of self-observation). Therefore, stimuli can be both public and private but, as mentioned, private stimulation at this stage is not the most relevant (it is assumed that survival will depend more on the effective control of the outer world, i.e., on the effective emotional bonding with the mother/father).

At stage 2, after multiple experiences with larger units of the previous phase, smaller units emerge: "I-see-an-apple, I-see-a-dog, I-see-water". From this experience, the functional unit "I-see" emerges as a common element of all the "I-see- $X$ " formulas. In phenomenological terms, the common and constant experience would be the experience of seeing, regardless of the objects and stimulus public situations (of seeing a car or an apple). It seems likely that the private stimulation associated with the activity of "seeing" acquires greater control over the " $I$ see" than the public parental control (which decreases gradually in normal and non-invalidating environments for the child). Thus, functional units are generated such as: "I see", "I have", "I want "and "I am", which can be combined with different specific objects. At this stage, a child can say things he never said before, for example: "I want music", or" "I watch soccer".

At stage 3, the simple unit "I" (the smallest of all) emerges and, at the same time, the experience of "I", which is the common element of all the "I... X" situations (I am the one who sees, wants, has, grabs, eats, etc.). Probably, the Self as a unit is under the stimulus control of the physical location of such experiences, that is, of the perspective or locus (place from which one "looks, feels, picks up, or wants"); in other words, from the perspective of the subject of the action (hence, it is easy to equate/feel/describe the self as an inner aspect).

The fact that the experience of the Self is a perspective instead of something physical has very important consequences. This Self can be described as constant, timeless or transcendent in time, invariant, inherent to the person; it is experienced as independent of age or of changing vicissitudes. It can be described as conscience, as something that is inside me or that is the core (remember the concept of perspective) and also as something alien (when the experience of describing is sometimes not controlled by the perspective, as in some hallucinatory or depersonalization experiences). The statement the Self is conscience refers to the fact that we are capable of observing our own behavior, realizing what we do, feel, or think, and the variables on which such behavior depends.

As argued, we learn to con-tact with our private experiences at very early ages. We need to understand the conscience as an activity and not as a thing/substance. "Things" are discriminant stimuli that control the Self, whether they are sensations, objects, or persons or one's own experience of thinking ("I-think"). The behaviors associated with being aware are closely related to the functional unit "Self", and it is extraordinarily simple for them to be made 
equivalent, considering them to be the same thing although they are different. That is why the animistic or mentalist tradition in psychology and in culture is so natural, so intuitive. And likewise, a process of reification occurs when the activity of thinking becomes thought or the activity of memorizing becomes memory, the activity of being aware becomes a Self like a thing/construct. Hence, we could have learned to build a belief about the Self as an object/substance; it is understood only in our environment because this experience probably not quite universal (Bukobza, 2007).

An additional verbal behavior is also necessary to complete the experience of the Self as a perspective (Kohlenberg, Tsai, Kanter \& Parker, 2009). This type of equivalence between the Self and thoughts, feelings, conscience, etc. can be explained through the Relational Frame Theory (Dymond \& Roche, 2013; Hayes, 1984; Hayes, Barnes-Holmes \& Roche, 2001). In general, this theory offers an explanation of human language and cognition, assuming that relational learning is the central point of complex human activities. Thus, "psychologically relating" means responding to an event in terms of another event (Hayes \& Wilson, 1993), like when responding to a metaphor. An example could be the statement: "Don't eat that; it's poison", when referring to the high quantity of saturated fat in a meal.

It is based on the fact that the stimulus relations derived from other verbal relations are generalized learned behaviors, in the same way that other response classes are learned. This theory argues that we also learn to respond according to deictic relational frames that are a central part of the development of the Self, especially in perspective-taking, the key to this development. They propose three basic deictic relational frames for perspective-taking: I-You, Here-There, and Now-Before (Kohlenberg, Tsai, Kanter \& Parker, 2009; McHugh, Stewart \& Hooper, 2012; Stewart, Villatte \& McHugh, 2012). These relational frames are trained very early in the child and become an inherent property of the person. When someone speaks to another person, he does so from the-located Self - "Here and Now" perspective about events that have occurred "There and Before". Deictic frames establish a distance or division between the speaker and what is spoken: the speaker is always "Here and Now" and what is spoken is "There and Before". Obviously, if this distance does not occur, it would be easy to confuse the Self with what is being said (something that is very relevant both in psychopathology and treatment). If the person is trapped in the There-Before without living the Here-Now, this would be a form hyper-reflective psychological experience, which could be a process that is present in many psychological disorders. Another example is when the person is incapable of having empathic experiences or cannot take on another person's perspective, as occurs in youths with dissocial disorders or in adults with narcissistic functioning. Currently, this interesting theoretical proposal is still being developed, and it is being applied to the formation of the Self and to perspective-taking (McHugh \& Stewart, 2012).

\section{Discussion}

The elusive nature of the Self as an important theme in psychology could be directly addressed to prevent its becoming stranded on aporetic representational proposals. In fact, in spite of the enormous relevance of the concept of the Self from neuroscientific approaches, as highlighted by Damasio (2003), the notion of the Self as a second-order idea is unsatisfactory (although undoubtedly of interest, inasmuch as the Self is presented as a product of the environmental stimulus and the body, modified by the experience of the perception of that 
stimulus). The difficulty to go beyond this probably lies in the emphasis of the mental representation (cerebral ideas/maps), which is perfectly avoidable even in Damasio's formulation. For example, the bodily changes we identify as hunger do not require the idea of hunger (Damasio, 2003) but rather personal bodily experiences associated with behavior-which is always intentional- (in fact, we eat before ideas of hunger exist and we even eat due to other causes that do not require the same bodily sensations). It is notable that, despite the large number of mental images and ideas inserted in the mind, in the end, the behavioral repertories are what is relevant (notwithstanding, as Damasio states, that someday someone will discover how neural patterns turn into mental images, and we will thus understand the formation of the Self). However the self-experience of seeing/feeling/thinking does not require necessarily representation in the mind; it occurs as a phenomenon in-itself in all senses, including common sense (Barresi, 2012). In any case, the brain needs language in order to be self-conscious (Neuman \& Nave, 2009).

It seems clear that the Self is not an immutable and fixed thing, but rather a process the experience of which may have a more or less stable appearance. Therein would lie the personality disorders and other everyday experiences in which the borders of the Self are blurred. A person who has difficulties knowing who he is, what he wants, feels or thinks depending on who else is present, or still worse, even when he is alone, will present important limitations in our social context, where the egoic experience is so omnipresent, sometimes quite so obsessive that the Self seems a “work of art” (Pérez-Álvarez \& García-Montes, 2004).

Moreover, the experience of ipseity is transcendent and one of the phenomena par excellence in human beings in the western culture (Barresi, 2012). The western mentalist and animistic tradition may be explained through process of reification (Honneth, 2007) or objectification, that is, turning an action or a verb into a noun. In our case, there is a relationship of functional equivalence between the multiple behaviors of "being aware of..." and the functional unit "Self" that is so merged that they are naturally and intuitively confused. Being aware of some psychological and physical event can lead one to think/feel that there is a Self within (literally inside) due to the deictic frames that allow perspective-taking and that establish the equivalence between the Self and the activity of being aware.

Comprehension of the Self in terms of perspective is extraordinarily important (Ataria, 2016); it allows us to understand its prototypical features (constancy, timelessness, transcendence, inwardness) without the need of mental supervisors or helmsmen (Popper \& Eccles, 1983) other than the person. In fact, in severe psychopathological processes, it is the person who loses his way (not the mind). Various anomalous learnings of the experience of the Self (ranging from ambivalent responses and punishment of private experiences, the invasion of these same experiences, categorization and perspective errors, etc.) would produce a broad array of psychological problems (Martin-Murcia \& Ferro, 2015).

Finally, since the conceptual difficulties in psychiatry and psychology no longer the sword of Damocles of these disciplines and it has suggested proposing philosophy as solving perspective (Fulford, Stanghellini \& Broome, 2004), we propose that phenomenological approach implicit in the radical behaviorism could be an optimal way to understand and explain certain characteristics about the construction of the Self. 


\section{References}

Ataria, Y. (2016). Body without a self, self without body. Journal of Theoretical and Philosophical Psychology, 36, 29-40.

Barresi, J. (2012). On seeing our selves and others as persons. New Ideas in Psychology, 30, 120-130.

Bennet, M., Dennet, D.C, Hacker, P. \& Searle, J. (2009). Neuroscience and Philosophy: Brain, Mind, and Language, New York: Columbia University.

Bukobza, G. (2007). The epistemological basis of selfhood. New Ideas in Psychology, 25, 3765.

Damasio, A. (2003). Looking for Spinoza: Joy, Sorrow, and the Feeling Brain, New York: Harcourt Brace \& Co.

Dymond, S. \& Roche, B. (2013). Advances in Relational Frame Theory. Research \& Application. Oakland: Context Press.

Freud, S. (1924). Formulations regarding the two principles in mental functioning, In Collected Papers (Vol. IV). London: Hogarth and Institute of Psychoanalysis.

Fuentes, J.B. \& Robles, F.J. (1992). The Phenomenological Nature of Skinner's Radical Behaviourism. Revista de Historia de la Psicología, 2, 61-67.

Fulford, K., Stanghellini, G. \& Broome, M. (2004). What can philosophy do for psychiatry?. World Psychiatry, 3, 130-135.

Hayes, S.C. (1984). Making sense of spirituality. Behaviorism, 12, 99-110.

Hayes, S.C. \& Wilson, K.G. (1993). Some applied implication of a contemporary behavioranalytic account of verbal events. The Behavior Analyst, 16, 83-301.

Hayes, S.C., Barnes-Holmes, D. \& Roche, B. (2001). Relational Frame Theory. A postskinnerian account of human language and cognition. New York: Kluwer Academic.

Honneth, A. (2007). Reification: A recognition-theoretical view, Oxford: Oxford University Press.

Kohlenberg, R.J. \& Tsai, M. (1991). Functional analytic psychotherapy. Creating intense and curative therapeutic relationship. New York: Plenum.

Kohlenberg, R.J., Tsai, M., Kanter, J. W. \& Parker, C.R. (2009). Self and Mindfulness. In Tsai, M., Kohlenberg, R.J., Kanter, J.W., Kohlenberg, B., Follette, W. \& Callaghan, G.M. (Eds.). A Guide to Functional Analytic Psychotherapy. Awareness, Courage, Love, and Behaviorism. (pp. 103-130). New York: Springer.

Martín Murcia, F. \& Ferro, R. (2015). Fenomenología y psicopatología en las terapias de tercera generación. Psychology, Society, \& Education, 7, 97-106.

McHugh, L., Stewart, I. \& Hooper, N. (2012). A Contemporary Functional Analytic Account of Perspective Taking. In L. McHugh \& I. Stewart (eds.) The Self and perspective taking. Contribution and applications from modern behavioral science (pp. 55-71). Reno: Context Press.

Neuman, Y. \& Nave, O. (2010). Why the brain needs language in order to be self-conscious, New Ideas in Psychology, 28, 37-48.

Pérez-Álvarez, M. \& García-Montes, J. M. (2004). Personality as a work of art. New Ideas in Psychology, 22, 157-173.

Popper, K.R. \& Eccles, J.C. (1983). The Self and its brain. NY: Routledge. 
Raeff, C. (2010). Self constructing activities. Theory \& Psychology, 20, 28-51.

Skinner, B.F. (1953). Science and human behavior. New York: Macmillan

Skinner, B. F. (1957). Verbal behavior. New York: Appleton-Century-Crofts.

Stewart, I., Villatte, J. \& McHugh, L. (2012). Approaches to Self. In L. McHugh \& I. Stewart (eds.), The Self and perspective taking. Contribution and applications from modern behavioral science (pp. 3-35). Reno: Context Press.

Zhao, S. (2014). Self as an emic object: A re-reading of William James on self. Theory \& Psychology, 24, 199-216. 